\title{
The effects of treadmill exercise on expression of UCP-2 of brown adipose tissue and TNF- $\alpha$ of soleus muscle in obese Zucker rats
}

\author{
Dong-Hee Kim¹, Seok-Hwan Kim ${ }^{1 *}$, Won-Hee $\mathrm{Kim}^{1}$ and Chae-Ryen Moon ${ }^{2}$ \\ ${ }^{1}$ Department of Physical Education, Chonnam National University, Gwangju, Korea \\ ${ }^{2}$ Department of Community Sports, Seonam University, Namwon, Korea
}

(Received: 2013/10/30, Revised: 2013/11/12, Published online: 2013/11/19)

\begin{abstract}
Sorts of abnormal state, obesity and inflammation are involved in a number of serious disease occurring and both of them became important research topics among molecular biologists. UCP-2 and TNF-a respectively reflecting obese and inflammatory status have often been used to evaluate the effects of independent variable, such as exercise, on them. Because exercise has shown its potent control on obesity and inflammation, it is necessary to determine if exercise is working via same bioindices. The purpose of this study was to determine the effects of different treadmill exercise intensities on UCP-2 of brown adipose tissue and TNF- $a$ of soleus muscle during 8 weeks in Zucker rat. Zucker rats were divided into four groups $(\mathrm{n}=7$ in each group): control group, low intensity exercise group, moderate intensity exercise group and high intensity exercise group. Zucker rats of the exercise groups were made to run on a motorized treadmill for 30 minutes once a day during 8 weeks. Rats were sacrificed 24 hours after the last bout of exercise. Blood glucose in Zucker rats were measured by Gluco-Card II. Brown adipose tissue were extracted to analyze the level of UCP-2 and TNF-a, respectively. UCP-2 and TNF-a were analyzed using the Western Blotting technique. Statistical techniques for data analysis were repeated measure ANOVA and one way ANOVA to determine the difference between groups, and for post hoc test was Duncan' test. The 5\% level of significance was utilized as the critical level for acceptance of hypotheses for the study. The following results were obtained from this study; UCP-2 protein expression of brown adipose tissue in Zucker rats were increased significantly following exercise of the low and moderate intensities compared to those of control group after 8 weeks. It was shown that TNF-a protein expression of soleus muscle in Zucker rats were decreased significantly following exercise of the low and moderate intensities compared to those of control group after 8 weeks. But no significant differences in levels of fasting glucose were shown between groups. The present data suggested that low and moderate intensities treadmill exercise may improve glycometabolism control and fat oxidation by up-regulating UCP-2 expression. In addition, we found low and moderate intensities reduce damages on skeletal muscle by down-regulation the TNF- $a$ in Zucker rats. Thus, the low and moderate intensity exercise are appropriate for anti-obesity and inflammatory effects.
\end{abstract}

Keywords: Obese Zucker Rats, UCP-2, TNF-a

\section{INTRODUCTION}

Exercise is widely known to have anti-obesity and anti-inflammatory effects [33]. Particularly, studies to identify mechanisms involved the anti-obesity effect are being conducted increasingly from the genetic point of view [25]. In anti-obesity effect, metabolisms in adipose tissue is as crucial as a metabolic rate of skeletal muscle. Among the adipose tissue metabolisms, exothermic reaction by thermogenesis in brown adipose tissue is important so studies on uncoupling protein (UCP) involved in generating energy in adipose tissue are being actively conducted. UCP is one of a protein groups participating thermogenesis and there are 5 main well-known isoforms including UCP-1 to UCP-5 [20]. These isoforms are tissue-specific and know to have a role in thermogenesis and increasing energy consumption by using protons in mitochondrial inner membrane. The protons generated in oxidative phosphorylation are used in thermogenesis by making energy as heat instead of ATP synthesis by UCP [27]. Eventually, up-regulation of UCP

* Corresponding author: Seok-Hwan Kim, Tel. 82-62-513-5636, Email. seokhwankim323@gmail.com

(c)2013 The Korean Society for Exercise Nutrition 
genes is reported to contribute to suppress ion of body fat generation and controlling obesity. In case of adults, adults have few brown adipose tissue so energy consumption via UCP-1 might be slight. It is presumed that there are mitochondrial proteins replacing UCP-1's role in tissues without UCP expression: UCP-2 and UCP-3 have reported as the substitution of UCP-1 [2,11]. [21] reported that swimming training effectively decreased circulating lipid levels, cholesterol, and fatty acids by inducing mRNAs of UCP-1,2, and 3 in obese mice. Endurance treadmill training also induced up-regulation of UCP mRNAs in brown adipose tissue [1] and mRNA of UCP-3 was reported to have a correlation with body fat [30]. The etiology of obesity is known to be related with various genes.

Adipose tissue, as a strong source of cytokine, is known to related to induction, extension, and progression of chronic inflammatory reaction by secreting various cytokines [33]. Especially, TNF-a (Tumor Necrosis Factor-a) gene expressed on macrophages in adipose tissue is said to be rapidly increased in case of obesity. Recently, tumor necrosis factor-a-308 promotor gene polymorphism (G-308A) due to $\mathrm{A}$ allele was proved to result in increasing gene transcription in adipose tissue [38].

In this way, an adipogenic increase in TNF-a is considered to induce reduction of muscle mass (sacropenic obesity) along with increased body fat [31].

Therefore, the purpose of this study is to suggest a molecular biological explanation on the effects of different treadmill exercise intensities on energy metabolism and inflammatory factors and to determine proper exercise intensity based on the results during 8 weeks in genetically obese Zucker rats.

\section{MATERIALS AND METHODS}

\section{Animals}

28, 10-week-old Zucker rats (SLC: Zucker fatty fa/fa rat, Japan) carrying genes related to obesity were used for the study for 8 weeks (Table 1). The animals were weighing 340-370g and supplied by Central Laboratory Animal Inc.

After 1 week of period of adaptation to experimental environments and treadmill training, animals were prepared for the experiments and were randomly divided into four groups ( $\mathrm{n}=7$ in each group): control group, low intensity exercise group, moderate intensity exercise group, and high intensity exercise group. Animals were housed two in a cage $(30 \mathrm{~cm} \times 20 \mathrm{~cm})$ under controlled temperature $\left(22-24^{\circ} \mathrm{C}\right)$, humidity $(50 \pm 10 \%)$, and lighting (12h of light; $12 \mathrm{hr}$ of dark in consideration of animals' nocturnal activity). Rats were fed with high fat diet (the diet consisted of $35 \%$ of carbohydrate, $20 \%$ of protein, and $45 \%$ of fat, supplied by Damul Science, Korea) with free access to water.

\section{Experimental protocols and exercising program}

Zucker rats had 8-week treadmill training with different exercise intensities and dependent variables included weight, blood glucose level, UCP-2, and TNF-a. Rats were divided into groups ( $\mathrm{n}=7$ in each group) including low intensity exercise group $\left(5-8 \mathrm{~m} / \mathrm{min}, 50-60 \% \quad \mathrm{VO}_{2} \mathrm{max}\right)$, moderate exercise intensity group $\left(14-16 \mathrm{~m} / \mathrm{min}, 65-70 \% \mathrm{VO}_{2} \mathrm{max}\right)$, and high intensity exercise group $\left(22-25 \mathrm{~m} / \mathrm{min}, 80 \% \mathrm{VO}_{2} \mathrm{max}\right)$ as described by Bedford and rats in the exercise groups were exercised by treadmill for $30 \mathrm{~min} /$ training and 4 days a week for 8 weeks.

Lightings were turned on at $8 \mathrm{PM}$ and off at $8 \mathrm{AM}$ (12h:12h) in accordance with nocturnal condition for maintaining biorhythm of animals and for effective training. In addition, in case of voluntary cease of exercise, continuous exercise was induced by a 10 -volt electronic stimulator set up under the belt of treadmill. However, electronic stimulation was replaced with a paper stick as possible to exclude the effect of electronic stimulation. Control group was left on small animal treadmill while exercise groups were exercising.

Con, control group; Low, low intensity exercise group; Moderate, moderate intensity exercise group; High, high intensity exercise group.

Table 1. Endurance training program

\begin{tabular}{lcccccc}
\hline \multirow{2}{*}{ Group } & $\mathrm{N}$ & $\begin{array}{c}\text { Duration } \\
\text { (weeks) }\end{array}$ & $\begin{array}{c}\text { Frequency } \\
(\text { days/week) }\end{array}$ & \multicolumn{2}{c}{ Intensity } & \multicolumn{2}{c}{$\begin{array}{c}\text { Exercise time } \\
(\text { min) }\end{array}$} \\
\hline Con & 7 & 8 & $*$ & speed (m/min) & grade $(\%)$ & $*$ \\
Low & 7 & 8 & 4 & $5-8$ & 0 & 30 \\
Moderate & 7 & 8 & 4 & $14-16$ & 0 & 30 \\
High & 7 & 8 & 4 & $22-25$ & 0 & 30 \\
\hline
\end{tabular}


Blood preparation and Analysis of weight and blood samples

Changes in the weight were measured 3 times (before exercise, 4th week, and 8th week) using a scale (TANIA CO., Japan). Blood samples were collected in $24 \mathrm{hr}$ with a at least 10-hr fasting period after maintaining a stable condition following 8-week exercise performance. Rats in each group were anesthetized with intraperitoneal injection of mixture solution of ketamine $(80 \mathrm{mg} / \mathrm{kg}$ ) and rompun (xylazine HCL, $5 \mathrm{mg} / \mathrm{kg}$ ) and fixed in a supine position without laparotomy. Blood was collected from left ventricles with 10ml (21 gage) syringes. Each blood sample was approximately over $5 \mathrm{ml}$. Drawn blood samples were kept in a freezer at below $-70^{\circ} \mathrm{C}$ after centrifugation for $3 \mathrm{~min}$ at $3000 \mathrm{rpm}$ in a plasma tube for plasma separation process as soon as blood was taken. Blood glucose was measured by a glucose monitor (Gluco-Card II, Kyto, Daichi Kaga-ku Co. Japan).

\section{Preparation and analysis of tissue samples}

Removal of soleus muscle and brown adipose tissue

Rats had prone position after collecting blood samples. Skeletal muscle samples from soleus muscle were taken from right hind limbs. Brown adipose tissue is usually distributed in axillar, shoulder bones, and on the periphery of back of neck and samples were collected from brown adipose tissue between scapulas. One inspector collected tissues from the same part of the body to minimize errors following differences of part of tissue removal. Tissue samples were kept in a freezer at below $-70^{\circ} \mathrm{C}$.

\section{Western blotting}

Each tissue sample (skeletal muscle and brown adipose tissue) was washed with PBS containing $37 \mathrm{mM} \mathrm{NaCl}, 2.7$ $\mathrm{mM} \mathrm{KCl}, 10 \mathrm{mM} \mathrm{Na} 2 \mathrm{PO}_{4}$, and $2 \mathrm{mM} \mathrm{KH} 2 \mathrm{PO} 4(\mathrm{pH} 7.4)$ and had ultrasonication in $0-200 \mu \mathrm{l}$ of triton lysis buffer (20 $\mathrm{mM}$ Tris, $\mathrm{pH}$ 7.4, $137 \mathrm{mM} \mathrm{NaCl}, 25 \mathrm{mM}$ B-blycerophosphate, pH 7.14, 2 mM sodium pyrophosphate, 2 mM EDTA, 1mM $\mathrm{Na}_{3} \mathrm{VO}_{4}, 1 \%$ Triron X-100, $10 \%$ glycerol, $5 \mu \mathrm{g} / \mathrm{ml}$ leupeptin, $5 \mu \mathrm{g} / \mathrm{ml}$ aprotinin, $3 \mathrm{uM}$ benzamidine, $0.5 \mathrm{mM}$ DTT, and $1 \mathrm{mM}$ PMSF). After that, protein was quantitively measured in each sample and $10 \mu \mathrm{g}$ of protein was used for western analysis. Expression of protein was confirmed by anti-UCP-2 antibodies (Santa Cruz Biotechnology, Santa Cruz, CA, USA). Polyvinylidene fluoride (PVDF) membrane (Pall, Mexico) was rested in blocking buffer (3\% BSA in TBS) at room temperature to block non-specific binding with antibodies for $1 \mathrm{hr}$ and reacted with protein samples for 1 and half $\mathrm{hr}$ at room temperature after the sample was diluted in the ratio of 1000 to 1

After that, membranes were treated with horseradish peroxidase (HRP)-conjugated secondary antibody (goat antirabbit, anti-rabbit IgG, Santacruz, California) and exposed to Kodak Scientific Imaging Film (Esteman Kodak Co., U.S.A). Each protein was quantitatively analyzed by I-solution software.

\section{Statistical analysis}

Data are presented as means \pm SD via SPSS package (version 17.0). Differences in weight and blood glucose between groups were assessed by repeated measures of ANOVA and relative differences in quantification values between proteins were evaluated by one way-ANOVA. Duncan's multiple comparison was used in post hoc test for significant difference. The P-values were accepted as statistically significant at $\mathrm{P} \leq 0.05$.

\section{RESULTS}

\section{Weight change following treadmill training in different exercise intensities}

In table 2, weights of control group increased after 8-week training with statistical significance compared to the pre-exercise weights and weights in 4th week of training: mean weights were $359.86 \pm 7.24 \mathrm{~g}$ before exercise, 470.57 $\pm 6.11 \mathrm{~g}$ in 4 th week, and $541.29 \pm 7.23 \mathrm{~g}$ in 8 th week of training.

In low intensity exercise group, mean weight increased in 8th week $(513.43 \pm 6.37 \mathrm{~g})$ with statistical significance compared to mean weight in 4 th week $(444.86 \pm 5.40 \mathrm{~g})$ and before exercise $(360.00 \pm 6.13 \mathrm{~g})$. Moderate intensity exercise

Table 2. The change of weight on the exercise intensity and exercise duration

(unit : g)

\begin{tabular}{lcccc}
\hline $\begin{array}{l}\text { Exercise } \\
\text { Intensity }\end{array}$ & Pre exercise $^{\mathrm{a}}$ & 4week $^{\mathrm{b}}$ & 8week $^{\mathrm{c}}$ & post-hoc \\
\hline Con $^{\mathrm{A}}$ & $359.86 \pm 7.24$ & $470.57 \pm 6.11$ & $541.29 \pm 7.23$ & $\mathrm{c}: \mathrm{a}, \mathrm{b}$ \\
Low $^{\mathrm{B}}$ & $360.00 \pm 6.13$ & $444.86 \pm 5.40$ & $513.43 \pm 6.37$ & $\mathrm{c}: \mathrm{a}, \mathrm{b}$ \\
Moderate $^{\mathrm{C}}$ & $359.43 \pm 6.88$ & $421.43 \pm 6.55$ & $492.14 \pm 9.75$ & $\mathrm{c}: \mathrm{a}$ \\
High $^{\mathrm{D}}$ & $359.86 \pm 6.31$ & $419.29 \pm 5.96$ & $488.57 \pm 10.88$ & $\mathrm{c}: \mathrm{a}$ \\
post-hoc & & A,B:C,D & A,B:C,D & \\
\hline
\end{tabular}

Means $\pm \mathrm{SD}$; Con, control group; Low, low intensity exercise group; Moderate, moderate intensity exercise group; High, high intensity exercise group. 
Table 3. The result of repeated ANOVA on the change of weight between intensity and duration

\begin{tabular}{lccccc}
\hline \multicolumn{1}{c}{ Source } & Type IIIss & DF & MS & F-Value & $\operatorname{Pr}>$ F \\
\hline Intensity & 16363.274 & 3 & 5454.425 & 98.369 & .0001 \\
Error & 1330.762 & 24 & 55.448 & & \\
Duration & 311112.071 & 1 & 311112.071 & 4701.523 & .0001 \\
Intensity*Duration & 6117.786 & 3 & 2039.262 & 30.817 & .0001 \\
Error (Duration) & 1588.143 & 24 & 66.173 & & \\
\hline
\end{tabular}

group also showed increased mean weight in 8th week $(492.14 \pm 9.75 \mathrm{~g})$ with statistical significance compared to 4 th week's mean weight $(421.43 \pm 6.55 \mathrm{~g})$ and weight before exercise $(359.43 \pm 6.88 \mathrm{~g})$. High intensity exercise group also had statistically significant weight increase in 8th week $(488.57 \pm 10.88 \mathrm{~g})$ compared to 4 th week's weight $(491.29 \pm$ $5.96 \mathrm{~g})$ and weight before exercise $(359.86 \pm 6.31 \mathrm{~g})$.

Results of repeated measures of ANOVA to assess differences in weight are shown in Table 3. Weigh differences depended on intensity, duration, and reciprocal action between intensity and duration of exercise with statistical significance.

\section{Blood glucose change following treadmill training in different exercise intensities}

In table 4 there are statistically significant changes in blood glucose level in control group (from $128.57 \pm 4.65 \mathrm{mg} / \mathrm{dl}$ before exercise to $171.00 \pm 5.23 \mathrm{mg} / \mathrm{dl}$ in 8 th week) and low intensity exercise group (from $127.86 \pm 4.88 \mathrm{mg} / \mathrm{dl}$ to 137.00 $\pm 4.20 \mathrm{mg} / \mathrm{dl}$ in 8 th week). No statistically significant changes in blood glucose level was shown in moderate intensity exercise group (from $127.71 \pm 4.89 \mathrm{mg} / \mathrm{dl}$ to $129.86 \pm 4.67$ $\mathrm{mg} / \mathrm{dl}$ in 8th week) and high intensity exercise group (from $128.71 \pm 3.04 \mathrm{mg} / \mathrm{dl}$ to $129.86 \pm 3.24 \mathrm{mg} / \mathrm{dl}$ in 8 th week). Blood glucose levels in moderate intensity exercise group and high intensity exercise group were low with statistical significance compared to blood glucose levels in control group and low intensity exercise group.

Results of repeated measures of ANOVA to evaluate differences in blood glucose level are shown in Table 5. and the differences depended on intensity, duration, and reciprocal action between intensity and duration of exercise with statistical significance.
Table 4. The change of blood glucose on the exercise intensity and exercise duration

(unit : $\mathrm{mg} / \mathrm{dl}$ )

\begin{tabular}{lccc}
\hline \multicolumn{1}{c}{$\begin{array}{c}\text { Exercise } \\
\text { Intensity }\end{array}$} & Pre exercise & 8 & poekt-hoc \\
\hline Con $^{\mathrm{A}}$ & $128.57 \pm 4.65$ & $171.00 \pm 5.23$ & $\mathrm{a}: \mathrm{b}, \mathrm{c}$ \\
Low $^{\mathrm{B}}$ & $127.86 \pm 4.88$ & $137.00 \pm 4.20$ & $\mathrm{a}: \mathrm{b}$ \\
Moderate $^{\mathrm{C}}$ & $127.71 \pm 4.89$ & $129.86 \pm 4.67$ & \\
High $^{\mathrm{D}}$ & $128.71 \pm 3.04$ & $129.86 \pm 3.24$ & \\
post-hoc & & A,B:C,D & \\
\hline
\end{tabular}

Means \pm SD; Con, control group; Low, low intensity exercise group; Moderate, moderate intensity exercise group; High, high intensity exercise group.

Table 5. The result of repeated ANOVA on the change of blood glucose between intensity and duration

\begin{tabular}{lccccc}
\hline \multicolumn{1}{c}{ Source } & Type IIIss & DF & MS & F-Value & $\operatorname{Pr}>F$ \\
\hline Intensity & 5490.381 & 3 & 1830.127 & 67.151 & .0001 \\
Error & 654.095 & 24 & 27.254 & & \\
Duration & 2633.143 & 1 & 2633.143 & 158.726 & .0001 \\
Intensity*Duration & 3980.714 & 3 & 1326.905 & 79.986 & .0001 \\
Error (Duration) & 398.143 & 24 & 16.589 & & \\
\hline
\end{tabular}

$U C P-2$ protein change following treadmill training in different exercise intensities

As shown in Table 6, expression of UCP-2 protein increased with statistical significance in control group $(75.14 \pm 12.58$

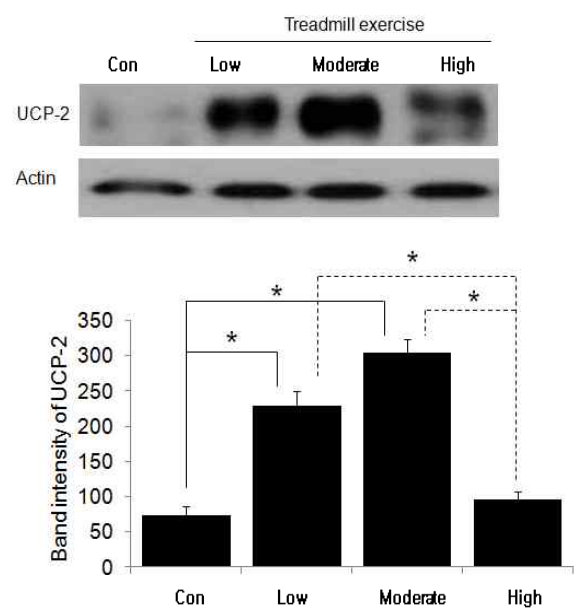

Fig. 4. The autoradiography and change of UCP-2 protein in brown adipose tissue after different treadmill exercise intensity. ${ }^{*} p<.05$ compared to the other groups. Values are means $\pm \operatorname{SEM}(n=7$ for all groups). (unit: band intensity).

Table 6. Change of UCP-2 protein in brown adipose tissue after different treadmill exercise intensity

(unit: band intensity)

\begin{tabular}{|c|c|c|c|c|c|c|}
\hline Group & Mean \pm SD & Type IIIss & DF & F-value & $\mathrm{p}$-value & post-hoc \\
\hline $\operatorname{Con}^{\mathrm{a}}(\mathrm{n}=7)$ & $75.14 \pm 12.58$ & \multirow{4}{*}{250567.250} & \multirow{4}{*}{3} & \multirow{4}{*}{317.33} & \multirow{4}{*}{0.001} & \multirow{4}{*}{$\mathrm{a}, \mathrm{d}: \mathrm{b}, \mathrm{c} \quad(\mathrm{p}=.001)$} \\
\hline Low $^{\mathrm{b}}$ & $227.43 \pm 21.31$ & & & & & \\
\hline Moderate $^{c}$ & $305.29 \pm 17.86$ & & & & & \\
\hline $\operatorname{High}^{\mathrm{d}}$ & $96.86 \pm 11.02$ & & & & & \\
\hline
\end{tabular}


band intensity), low intensity exercise group $(227.43 \pm 21.31$ band intensity), and moderate intensity exercise group (305.29 \pm 17.86 band intensity). However, high intensity exercise group did not show statistically significant difference in protein expression $(96.86 \pm 11.02$ band intensity) compared to the protein expression of control group.

Fig. 1. The autoradiography and change of UCP-2 protein in brown adipose tissue after different treadmill exercise intensity. ${ }^{*} \mathrm{p}<.05$ compared to the other groups. Values are means \pm SEM ( $n=7$ for all groups). (unit: band intensity).

\section{TNF-a protein change following treadmill training in different exercise intensities}

Changes in TNF-a protein expression are shown in Fig. 2 and Table 7. In table 7, TNF-a protein expression decreased with statistical significance in control group $(253.00 \pm 24.33$ band intensity), low intensity exercise group $(68.14 \pm 9.58$ band intensity), and moderate intensity exercise group (77.29 \pm 8.06 band intensity). However, no statistically significant changes in TNF-a protein expression was shown in high intensity exercise group (235.86 \pm 14.62 band intensity) compared to TNF-a protein expression in control group.

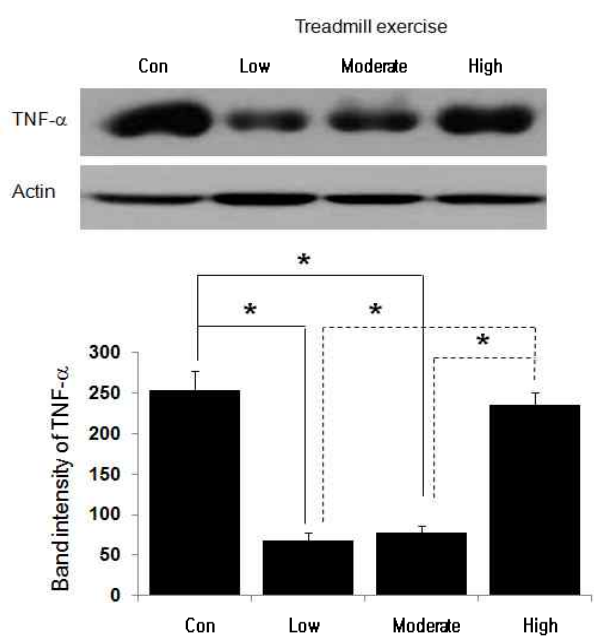

Fig 2. The autoradiography and change of TNF- $a$ protein in soleus after different treadmill exercise intensity. ${ }^{*} p<.05$ compared to the other groups. Values are means \pm SEM ( $n=7$ for all groups). (unit: band intensity).

\section{DISCUSSION}

The purpose of this study is to suggest a molecular biological explanation on the effects of different treadmill exercise intensities on energy metabolism and inflammatory factors and to determine proper exercise intensity based on the results during 8 weeks in genetically obese Zucker rats.

Body weight is widely known to be changed by diet and energy consumption, exercise. After 8-week training, obese Zucker rats showed an increase in body weight with statistical significance in both control and exercise groups. This is considered as a result of natural growth, which is explained by the fact that rats were in the growing period and fed with high fat diet. However, the statistically significant decrease in body weight in exercise group compared to control group's body weight change indicates a positive effect of exercise. [19] reported in a 8-week study with SD male mice fed with high fat diet that swimming training group showed a tendency of having low body weight compared to control group even though body weights of both exercise and control groups increased gradually until 32nd day of experiment. Long term feeding with high fat diet or obesity is known to decrease glucose availability due to an increase in fatty acid use following fat metabolism and to induce hyperinsulinemia and insulin resistance due to increase in blood glucose and excessive secretion of insulin [22].

[14] reported that a 3-week high fat diet decreased glucose availability in rats and induced insulin resistance by two mechanisms: decreased glucose oxidation and decreased storage of glycogen. Particularly, insulin resistance in skeletal muscle is presumed to be caused by promoted intracellular glucose-fatty acid cycle followed by increases in free fatty acids in blood and neutral fats in skeletal muscle. Related to this, [15] induced insulin resistance in mice with a 3-week high fat diet by increased fat oxidation which damaged glucose metabolism including decrease in glycogen synthase activity. [28] reported blood glucose level and insulin level improved by increase in UCP in mice with high fat diet and [18] reported long term exercise brought a positive effect in blood glucose control and insulin sensitivity.

In this study, post-exercise blood glucose level was higher than pre-exercise blood glucose but low fasting blood glucose

Table 7. Change of TNF-a protein in soleus muscle after different treadmill exercise intensity

(unit: band intensity)

\begin{tabular}{lccccc}
\hline & Mean \pm SD & Type IIIss & DF & F-value & p-value \\
\hline Con $^{\mathrm{a}}(\mathrm{n}=7)$ & $253.00 \pm 24.33$ & & & & post-hoc \\
Low $^{\mathrm{b}}$ & $68.14 \pm 9.58$ & 207721.714 & 3 & 287.75 & $0.001 \quad$ a,d:b,c (p=.001) \\
Moderate $^{\mathrm{c}}$ & $77.29 \pm 8.06$ & & & & \\
High $^{\mathrm{d}}$ & $235.86 \pm 14.62$ & & & \\
\hline
\end{tabular}


in exercise groups indicates glycometabolism disorder and imperfect function of insulin due to obesity can be improved by exercise. In addition, a statistically significant decrease in blood glucose of moderate and high intensity exercise groups after a 8-week treadmill training can be explained by an increase in glycogen synthesis after exercise induced by glycogenolysis in the liver and active muscle due to glycogen phosphorylase activity followed by increases reactions of sympathetic hormones [13]. This study also showed a correlation of blood glucose level with UCP-2 expression so studies hearafter should be pursued for elucidate various factors such as proteins or enzymes acting on insulin signal pathways in skeletal muscle. UCP gene expression is reported to inhibit body fat accumulation and to control obesity [28] Among UCP genes, UCP-2 is know to regulate energy metabolism, related directly to $\beta-2,3$ adrenalin receptors and to be clearly involved in obesity [36]. In other words, a decrease in energy consumption induces up-regulation of UCP-2 expression while an increase in energy consumption induces downregulation of UCP-2 expression. UCP-2 decreases lipolysis and increases respiration volume [40] and gene mutation of UCP-2 is reported to be more exposed to the danger of obesity due to decreases in exercise efficiency and energy metabolism [4]. [5] reported that a decreased UCP-2 expression in the pancreas of UCP-2 knock-out transgenic mice induced increased secretion of insulin followed by a decrease in blood glucose level and marked improvement in glycometabolism along with increased insulin secretion due to a decrease in UCP-2 expression in ob/ob mice, a model animal of obesity and hyperinsulinemia. These results prove that UCP-2 can be a factor regulating pancreatic insulin secretion and UCP-2 is paid attention as a regulator of insulin secretion instead of being related to insulin sensitivity.

So far, Regulation of UCP-2 gene expression and factors related to metabolic functions of UCP-2 are not clear but [11, 1] elucidated heat generating function of UCP-2 and 3 in skeletal muscle and adipose tissue which are crucial for heat generation and energy homeostasis by showing induction of heat generation through oxidative phosphorylation by UCP-2 and 3 in transgenic yeast and myofibroblast.

These studies support that UCP induces a decrease in body fat, and improvement in insulin sensitivity by regulating fat or energy metabolism so it can be used for prevention and treatment of adult diseases such as diabetes melitus or obesity.

Based on the previous studies on a correlation between UCP expression and body fat, this study showed a statistically significant increase of UCP-2 expression in low and moderate intensity exercise groups compared to control group and this means UCP affected to the physiological function that uses fat preferentially as an energy source followed by metabolic adaption to a supply of free fatty acids. Characteristically, low intensity exercise has an exercise form through slow muscle containing abundant mitochondria and with high oxidative enzymatic activity $[1,37,13]$. In addition, high intensity exercise group showed decreased UCP-2 expression compared to low intensity exercise group is considered due to a decrease in UCP mRNA expression to increase ATP production as a part of enhancement exercise efficiency through inhibiting unnecessary energy consumption following a decrease in glucose storage level.

TNF-a in skeletal muscle activates $\mathrm{p} 38$ and NF- $\mathrm{BB}$ which induce up-regulation of MAFb atrogin-1 and MuRF1 so eventually induce muscle contraction [29].

Therefore, TNF-a expression increases in obesity and aging process, playing a role in body fat accumulation and muscle mass reduction also in insulin resistance and an increase in metabolic diseases [26].

Insulin resistance due to obesity or high fat diet accompanies inflammatory reactions in adipose tissue along with fat accumulation. The inflammatory reaction is hypothesized to induce insulin resistance by inflammatory cytokine secretion from lipocytes and activated macrophages in adipose tissue [39]. However, previous studies suggested that TNF-a expression analysis in active tissue is more effective to evaluate the functions of inflammatory cytokines during exercise because inflammatory cytokines such as TNF-a are variably secreted in individuals and act on various body systems $[7,6]$. [19] reported significant decreases in visceral fat, body fat percentage, and TNF-a decreased and improvement in insulin resistance after a 10-week aerobic and resistive exercises in abdominal obesity group. [16] reported a decrease in TNF-a as a result of a 10-month experiment of 3 times a week, 45 $\mathrm{min} /$ exercise in aerobic and flexibility exercise group and weight training group of adults. [9] reported a decrease in IL-6 in stable condition, a decrease in TNF-a in moderate intensity exercise group, an increase in TNF-after high intensity exercise after a 9-week training of aerobic exercises including cycling and jogging in obese adults with over $29 \mathrm{~kg} / \mathrm{m}^{2}$ of BMI.

[10] showed increased TNF-a after 60-min ergometric cycling exercise with $65 \% \mathrm{VO}_{2} \max$ in healthy men and women in the average age of 27 . Like above, there are various reports on effects of exercise related to TNF-a including a decrease or no changes in TNF-a with moderate intensity exercise [8] and an increase in TNF-a with high intensity exercise [23]. [32] reported decreased TNF-a after a 12-week cycling ergometric exercise of 5 times a week, 30min/exercise with $70 \%$ HRmax for 8 obese women of over 27.8 of BMI. 
[12] reported a decrease in TNF-a concentration after a 3-month resistive training of 3 times a week, $50-90 \mathrm{~min} /$ exercise for obese adults with over $30 \%$ of body fat ratio. [17] reported that IL-6 and TNF-a secreted adipose tissue of obese individuals decreased by anti-obesity treatment, especially by exercising programs. Blood TNF-a level was reported high in a obese group with high body fat level, particularly in high abdominal fat accumulation groups [24] and is known to decrease after a certain period of time of regular exercising program [34].

In this study, TNF-a expression in skeletal muscle did not show a significant difference between high intensity exercise group and control group but a significant decrease between low and moderate intensity groups and control group. [35] showed that a regular exercise led decreases in TNF-a and body weight and an increase in HDL-C in obesity group. [3] reported that a regular exercise resulted in decreased level of TNF-a in resting phase compared to control obesity group even though a little amount of TNF-a was expressed during exercise.

In conclusion, low and moderate intensity exercise groups showed a significant increase in UCP-2 expression and a significant decrease in TNF-a expression compared to the other groups.

After considering all the results, the treadmill training brought a positive effect on fat oxidation and glycometabolism by up-regulation of UCP-2 protein expression in brown adipose tissue and played a role in reducing muscular damage of skeletal muscle by down-regulating TNF-a protein expression in soleus muscle. The proper exercise intensity for positive anti-obesity and anti-inflammatory effects is considered low and/or moderate.

\section{CONCLUSION}

The purpose of this study is to suggest a molecular biological explanation on the effects of different treadmill exercise intensities on energy metabolism and inflammatory factors and to determine proper exercise intensity based on the results during 8 weeks in genetically obese Zucker rats.

1. Weights of Zucker rats decreased in 4th and 8th week of training with statistical significance in moderate and high intensity exercise groups compared to control and low intensity exercise groups after a 8-week treadmill training of different intensities.

2. Blood glucose of Zucker rats decreased in 8th week of training with statistical significance in moderate and high intensity exercise groups compared to control and low intensity exercise groups after a 8-week treadmill training of different intensities.

3. UCP-2 protein expression in brown adipose tissue of Zucker rats was high with statistical significance in low and moderate intensity exercise groups compared to control and high intensity exercise groups after a 8-week treadmill training of different intensities.

4. TNF-a protein expression in soleus muscle of Zucker rats was low with statistical significance in low and moderate intensity exercise groups compared to control and high intensity exercise groups after a 8-week treadmill training of different intensities.

In conclusion, a 8-week treadmill training have a positive effect on fat oxidation and glycometabolism by up-regulation of UCP-2 protein expression in brown adipose tissue and played a role in reducing muscular damage of skeletal muscle by down-regulating TNF-a protein expression in soleus muscle. The proper exercise intensity for positive anti-obesity and anti-inflammatory effects is considered low and/or moderate.

\section{REFERENCES}

[1] Boss O, Samec S, Desplanches D, Mayet MH, Seydoux J, Muzzin P, Giacobino JP. Effect of endurance training on mRNA expression of uncoupling proteins 1,2 , and 3 in the ratFASEBJ 1998;12(3):335-339.

[2] Boss O, Samec S, Paoloni GA, Rossier C, Dulloo A, Seydoux J, Muzzin P, Giacobino JP. Uncoupling protein-3: a new member of the mitochondrial carrier family with tissue-specific expressionFEBS Let 1997; 408(1):39-42.

[3] Bruunsgaard H, Bjerregaad E, Schroll M. \& Pedersen BK. Muscle strength after resistance training is inversely correlated with baseline levels of soluble tumor necrosis factor receptors in the oldest old J Am Geriatr Soc 2004;52(2):237-241.

[4] Buemann B, Schieming B, Toubro S, Bibby BM, Sørensen T, Dalgaard L, Pedersen O, \& Astrup A. The association between the val/ala-55 polymorphism of the uncoupling protein 2 gene and exercise efficiencyInt $\mathrm{J}$ Obes 2001;25(4):467-471.

[5] Chen Bing, Micheal Brown, Peter King, Peter Collins, Michael J, Tisdale \& Gareth Williams. Increased gene expression of brown fat UCP1 and skeletal muscle UCP2 and UCP3 in MAC16-induced cancer CachexiaCancer Research 2000;60:2405-2410.

[6] Conraads VM, Beckers P, Bosmans J, De Clerck LS, 
Stevens WJ, Vrints CJ, Brutsaert DL. Combined endurance/resistance training reduces plasma TNF-alpha receptor levels in patients with chronic heart failure and coronary artery diseaseEur Heart J 2002;23(23):18541860.

[7] Dibbs Z, Kurrelmeyer K, Kalra D, Seta Y, Wang F, Bozkurt, Baumgarten G, Sivasubramanian N, Mann DL. Cytokines in heart failure: pathogenetic mechanisms and potential treatmentProc. Assoc. Am. Physicians 1999; 111(5):423-438.

[8] Drenth JP, Krebber TJ, Bijzet, Van Der Meer JW. Increased circulating cytokine receptors and ex vivo interleukin-1 receptor antagonist and interleukin-1beta production but decreased tumor necrosis factor-alpha production after a 5-km runEUR J Clin Invest 1998;28: 866-872.

[9] Dvorakova-Lorenzova A, Suchanek P, Havel PJ, Stavek P, Karasova L, Valenta Z, Tintera J, Poledne R. The decrease in C-reactive protein concentration after diet and physical activity induced weight reduction is associated with changes in plasma lipids, but not interleukin-6 or adiponectin Metabolism 2006;55(3): 359-365.

[10] Ferguson MA, White LJ, McCoy S, Kim HW, Petty T, Wilsey J. Plasma adiponectin response to acute exercise in healthy subjectsEurJ Appl Physiol 2004;91(2-3): 324-329.

[11] Fleury C, Neverova M, Collins S, Raimbault S, Champigny O, Levi MC, Bouillaud F, Seldin M F, Surwit RS, Ricquier D, Warden $\mathrm{CH}$. Uncoupling protein-2: a novel gene linked to obesity and hyperinsulinemiaNat Genet 1997;15(3):269-272.

[12] Jeffrey SG, Bo C, Deborah CR, Kevin EY, Clay FS. Resistance exercise decreases skeletal muscle tumor necrosis factor $\mathrm{a}$ in frail elderly humans.FASEB $\mathrm{J}$ 2001;15:475-482.

[13] Jeong IG, Yoon JH.Human Performance \& Exercise Physiology 2006;80-115. Seoul: Daekyung Books.

[14] Kim CH, Park GY, Hong SG, Lee HG, Lee KO. Effect of exercise training on insulin sensitivity and intracelluar glucose metabolism in skeletal muscle of high fat-fed RatsDiabetes J 1998;22(2):231-242.

[15] Kim CH, Youn JH, Park JY, Hong SK, Park KS, Park SW, Suh KI, \& Lee KU. Effects of high-fat diet and exercise training on intracellular glucose metabolism in ratsAm J Physiol Endocrinol Metab 2000;278:E977E984.

[16] Kohut ML, McCann DA, Russell DW, Konopka DN, Cunnick JE, Franke WD, Castillo MC, Reighard AE,
Vanderah E. Aerobic exercise, but not flexibility/ resistance exercise, reduces serum IL-18, CRP, and IL-6 independent of ß-blockers, BMI, and psychosocial factors in older adultsBrain Behav Immun 2006;20(3): 201-209.

[17] Kondo T, Kobayashi I, Murakami M. Effect of exercise on circulating adipokine levels in obese young women Endocrine Journal 2006;53(2):189-195.

[18] Kraemer RR, Chu H, Castracane VD. Leptin and exerciseExp Biol Med 2002;227:701-708.

[19] Kwon YC, Youn MS, Park SKJ. The effect of combined training on lymphocyte and TNF-a concentration in obse adolesentThe Korean Journal of Physical Education 2003;42(2):335-345.

[20] Mao W, Yu X, X, Zhong A, Li W, Brush J, Sherwood SW, Adams SH, \& Pan G. UCP4, a novel brain-specific mitochondrial protein that reduces membrane potential in mammalian cellsFEBS Lett 1999;443(3):326-330.

[21] Oh KS, Kim EY, Yoon M, \& Lee CM. Swim training improves leptin receptor deficiency-induced obesity and lipid disorder by activating uncoupling proteinsExp Mol Med 2007;39(3):385-394.

[22] Park SY, Kim YW, Kim JY, Jang EC, Doh KO, \& Lee SK. Effect of High Fat Diet on Insulin Resistance: Dietary Fat Versus Visceral Fat MassJ Korean Med Sci 2001;16:386-390.

[23] Pedersen BK, Adam S, \& Peter S. Exercise and interleukin-6Curr Opin Hematol 2001;8:137-141.

[24] Perry CD, Alekel DL, Ritland LM, Bhupathiraju SN, Stewart JW, Hanson LN, Matvienko OA, Kohut ML, Reddy MB, Van Loan MD, \& Genschel U. Centrally located body fat is related to inflammatory markers in healthy postmenopausal womenMenopause 2008;15(4): $1-9$.

[25] Peterson JM, Bryner RW, Frisbee JC, \& Alway SE. Effects of exercise and Obesity on UCP-3 Content in rat hindlimb musclesMed Sci Sports Exerc 2008;40(9): 1616-1622.

[26] Reaven GM. Insulin resistance, the insulin resistance syndrome, and cardiovascular disease. Panmin-erva Med 2005;47(4):201-210.

[27] Ricquier D. Fundamental mechanisms of thermogenesis C R Biol 2006;329(8):578-586.

[28] Rippe C, Berger K, Boeirs C, Ricquier D, \& Erlanson AC. Effect of high fat diet, surrounding temperature, and enterostatin on uncoupling protein gene expressionAm $\mathrm{J}$ Physiol Endocrinol Metab 2000;279:E293-E300.

[29] Roubenoff R. Sarcopenic obesity: the confluence of two epidemicsObes Res 2004;12(6):887-888. 
[30] Schrauwen P, Saris WH, \& Hesselink MK. An alternative function for human uncoupling protein 3: protection of mitochondria against accumulation of nonesterified fatty acids inside the mitochondrial matrixFASEB J 2001; 15(13):2497-2502.

[31] Shoelson SE, Lee J, \& Goldfine AB. Inflammation and insulin resistanceJ Clin Invest 2006;116(7):1793-1801.

[32] Straczkowski M, Kowalska I, Dzienis-Straczkowska S, Stepien A, Skibinska E, Szelachowska M, Kinalska I. Changes in tumor necrosis factor-alpha system and insulin sensitivity during an exercise training program in obese women with normal and impaired glucose toleranceEur J Endocrinol 2001;145:273-280.

[33] Teixeira de, Lemos E, Reis F, Baptista S, Pinto R, Sepodes B, Vala H, Rocha-Pereira P, Correia da, Silva G, Teixeira N, Silva AS, Carvalho L, Teixeira F, \& Das UN. Exercise training decreases proinflammatory profile in Zucker diabetic (type 2) fatty ratsNutrition 2009; 25(3):330-339.

[34] Trayhurn P, \& Wood IS. Signaling role of adipose tissue: adipokines and inflammation in obesityBiochem Soc Trans 2005;33:1078-1081

[35] Tsukui S, Kanda T, Nara M, Nishino M, Kondo T, \& Kobayashi I. Moderate-intensity regular exercise decreases serum tumor necrosis factor-alpha and $\mathrm{HbA}_{1 \mathrm{c}}$ levels in healthy woman. International Journal of Obesity and
Related Metabolic Disorders 2000;24(9):1207-1211.

[36] Vidal-Puig A, Solanes G, Grujic D, Flier JS, \& Lowell BB. UCP3: An uncoupling protein homologue expressed preferentially and abundantly in skeletal muscle and brown adipose tissue. Biochem Biophys Res Commun 1997;235(1):79-82.

[37] Weigle DS, Selfridge LE, Schwartz MW, Seeley RJ, Cummings DE, Havel PJ, Kuijper JL, \& Rio HB. Elevated free fatty acids induce uncoupling protein 3 expression in muscle: a potential explanation for the effect of fastingDiabetes 1998;47:298-302.

[38] Wilson AG, di Giovine FS, Blakemore AI, \& Duff GW. Single base polymorphism in the human tumour necrosis factor alpha (TNF alpha) gene detectable by NcoI restriction of PCR product. HumMol Genet 1992;1(5):353.

[39] Xu H, Barnes GT, Yang Q, Tan G, Yang D, Chou CJ, Sole J, Nichols A, Ross JS, Tartaglia LA, \& Chen H. Chronic inflammation in fat plays a crucial role in the development of obesity- related insulin resistanceJ Clin Invest 2003;112(12):1821-1830.

[40] Yanovski JA, Diament AL, Sovik KN, Nguyen TT, Hongzhe Li Sebring NG, \& Warden CH. Associations between uncoupling protein 2, body composition, and resting energy expenditure in lean and obese African American, White and Asian childrenAm J Clin Nutr 2000;(6):1405-1420. 